\title{
Detección por reacción en cadena de la polimerasa de transcriptasa inversa del virus de la fiebre amarilla en monos silvestres: una herramienta sensible para la vigilancia epidemiológica
}

\author{
Jairo A. Méndez ${ }^{1}$, Édgar Parra ${ }^{2}$, Marcela Neira ${ }^{2}$, Gloria J. Rey ${ }^{1}$ \\ ${ }^{1}$ Grupo de Virología, Instituto Nacional de Salud, Bogotá, D. C., Colombia. \\ ${ }^{2}$ Grupo de Patología, Instituto Nacional de Salud, Bogotá, D. C., Colombia. \\ Introducción. La fiebre amarilla es una enfermedad zoonótica mantenida en la naturaleza por \\ primates no humanos; su vigilancia por técnicas sensibles de laboratorio es necesaria para \\ hacer evidente la actividad viral en territorio selvático. \\ Objetivo. Detectar el virus de la fiebre amarilla en muestras de tejido hepático de primates no \\ humanos, mediante la técnica de reacción en cadena de la polimerasa de transcriptasa inversa \\ (RT-PCR) con iniciadores diagnósticos específicos. \\ Materiales y métodos. Se procesaron muestras de tejido hepático de cinco monos del genero \\ Alouatta spp. encontrados muertos en territorio selvático de los departamentos de Cesar y \\ Magdalena entre diciembre de 2003 y junio de 2004. Las muestras fueron tratadas con una \\ solución de lisis para aislar el ARN viral que, posteriormente, fue utilizado en una RT-PCR, \\ utilizando iniciadores específicos para fiebre amarilla; paralelamente, se identificaron proteínas \\ virales mediante inmunohistoquímica sobre cortes de tejido hepático incluidos en parafina. \\ Resultados. Se obtuvieron productos de amplificación del tamaño esperado, (424pb) en \\ cuatro de las muestras analizadas; estas muestras mostraron, además, una reacción \\ inmunohistoquímica positiva, lo que confirma la presencia del virus. \\ Conclusión. El hallazgo del virus de la fiebre amarilla en monos silvestres representa una \\ evidencia de su actividad enzoótica en nuestro territorio, que incrementa el riesgo de \\ transmisión a humanos y de urbanización por procesos de migración de la población. La \\ detección por técnicas moleculares rápidas y específicas del virus en monos silvestres \\ representa una herramienta de vigilancia epidemiológica que permite activar de manera precoz \\ los sistemas de control necesarios para impedir brotes y epidemias.
}

Palabras clave: fiebre amarilla/virología, reacción en cadena de la polimerasa de transcriptasa inversa, Alouatta, primates, vigilancia epidemiológica.

Detection of yellow fever virus by reverse transcriptase polymerase chain reaction in wild monkeys: a sensitive tool for epidemiologic surveillance

Introduction. Yellow fever is a zoonotic infection maintained in nature by non-human primates. Appropriate surveillance with sensitive laboratory techniques is necessary to evidence viral activity in the tropical forest habitats of these primates.

Objective. Yellow fever virus was detected in hepatic tissue samples from non-human primates by reverse transcriptase polymerase chain reaction (RT-PCR) technique using specific primers for diagnosis.

Materials and methods. Hepatic tissue samples were processed from five monkeys belonging genus Alouatta spp found dead in sylvatic areas of Cesar and Magdalena Provinces, Colombia, between December 2003 and June 2004. Samples were treated with lysis buffer prior to the isolation of viral RNA, which was then subjected to reverse transcriptase polymerase chain reaction (RT-PCR) using yellow fever-specific primers. Simultaneously, viral proteins were identified by immunohistochemistry on parafin-embedded hepatic tissue. 


\begin{abstract}
Results. The PCR method amplified fragments of the expected size (424 bp) in four of the tested samples. In addition, these samples showed a positive reaction by immunohistochemistry, supporting the evidence that the virus was present.

Conclusion. The detection of yellow fever virus in wild monkeys was clear evidence of enzootic activity in northern Colombia. Increased probability of yellow fever transmission among human populations is indicated due to urbanization processes as a consequence of forced migration and displacement of the human populations. Molecular tests for rapid and specific detection of yellow fever in tissue samples of non-human primates is an important tool for epidemiologic surveillance. Rapid virus identification will permit the timely activation of control systems for prevention of further cases and epidemic situations.
\end{abstract}

Key words: Yellow fever/virology, reverse transcriptase polymerase chain reaction, Alouatta, primates, epidemiologic surveillance.

La fiebre amarilla es quizá la fiebre hemorrágica viral más antigua, descrita en manuscritos mayas que datan de 1648, aunque análisis detallados del genoma han demostrado que el virus de la fiebre amarilla evolucionó de otro arbovirus hace, aproximadamente, 3.000 años, probablemente en África $(1,2)$.

A pesar de la existencia de una vacuna eficaz, la fiebre amarilla continúa siendo hoy en día una importante causa de morbilidad y mortalidad que afecta regiones tropicales y subtropicales, principalmente de África y Suramérica, donde se reportan, aproximadamente, 5.000 y 300 casos al año, respectivamente (3-5). Aunque la Organización Panamericana de la Salud (OPS) reportó oficialmente 2.022 casos en el periodo 1986-1995 en Suramérica, se piensa que estos datos subestiman la cantidad real, ya que los casos menos graves no se reconocen o simplemente no se reportan. De hecho, algunos autores creen que la verdadera incidencia de la enfermedad es de 5 a 10 veces mayor que la oficial $(3,5)$.

En Colombia existen cerca de 5 millones de personas en riesgo potencial de padecer fiebre amarilla por el hecho de vivir en zonas muy cercanas a territorios selváticos donde ocurren casos esporádicos de la enfermedad, principalmente, el piedemonte de las cordilleras Central y

\footnotetext{
Correspondencia:

Jairo A. Méndez, Laboratorio de Virología, Instituto Nacional de Salud, INS, Av. Calle 26 No. 51-20, Bogotá, D. C., Colombia.

Teléfono: $+57(1) 2207700$, extensión 549; fax: +57(1) 220 0928

jmendez@ins.gov.co
}

Recibido: 08/03/07; aceptado: 19/06/07
Oriental, la cuenca de los ríos Magdalena, Orinoco, Atrato y Catatumbo, y las estribaciones de la Sierra Nevada de Santa Marta (6-13).

La fiebre amarilla es una infección zoonótica mantenida en la naturaleza por primates no humanos y mosquitos de hábitos diurnos, tales como Haemagogus spp. en América y Aedes spp. en África. Diferentes primates selváticos presentan los efectos viscerotrópicos del virus; los monos aulladores (Aloutta seniculus) son los más susceptibles, seguidos de los monos araña (Saymiri spp.), los monos ardilla (Ateles sp.) y los monos lechuza (Aotus trivirgatus) (14-19).

Teniendo en cuenta que el hallazgo de cadáveres de alguna de estas especies de primates en zonas selváticas constituye una alarma sobre la actividad viral $(16,20)$, es necesario complementar los sistemas de vigilancia mediante la determinación rápida del virus en muestras obtenidas por viscerotomía realizada a estos animales. Por tal motivo, hemos adaptado en nuestro laboratorio la técnica de reacción en cadena de la polimerasa de transcriptasa inversa (RT-PCR) para la detección rápida y específica del virus de la fiebre amarilla en tejido, utilizando como modelo muestras hepáticas de cinco monos aulladores encontrados muertos en zona selvática de los departamentos de Cesar y Magdalena, para demostrar de esta manera la actividad selvática en nuestro territorio.

\section{Materiales y métodos \\ Muestras de tejido}

Se obtuvieron muestras de tejido hepático de cuatro primates del género $A$. seniculus (mono 
aullador o mono cotudo) encontrados muertos en territorio selvático del departamento del Cesar (vereda Los Bezotes, vereda Pitillas, vía La Mesa y municipio de La Paz), durante el periodo comprendido entre el 26 de diciembre de 2003 y el 30 de junio de 2004, y uno encontrado en el departamento del Magdalena, el 14 de enero de 2004. Las muestras fueron enviadas al Laboratorio de Virología del Instituto Nacional de Salud en solución salina estéril (con bloques de refrigeración para mantener la temperatura alrededor de $4^{\circ} \mathrm{C}$ ) y al Laboratorio de Patología en solución de formol tamponado al 10\%; una de las muestras provenientes del Cesar (del municipio de La Paz) llegó al laboratorio sin refrigerar y en mal estado de conservación.

\section{Extracción y purificación del ARN}

Aproximadamente, $1 \mathrm{~g}$ de cada muestra de tejido hepático fue tratado con $500 \mu \mathrm{l}$ de solución de lisis (tris- $\mathrm{HCl} 100 \mathrm{mM} \mathrm{pH} \mathrm{8,5,} \mathrm{EDTA} \mathrm{0,5M,} \mathrm{SDS}$ $10 \%$, proteinasa $\mathrm{K} 25 \mathrm{mg} / \mathrm{ml}$ y 20 unidades de inhibidor de ARNasa) en baño serológico a $56^{\circ} \mathrm{C}$ por 3 a 5 horas. Para realizar el aislamiento del ARN viral se tomaron $300 \mu$ del producto lisado y se trataron con $700 \mu$ I de Trizol LS ${ }^{\circledR}$ (Invitrogen) durante 5 minutos; posteriormente, se adicionaron $200 \mu \mathrm{l}$ de cloroformo a cada muestra y se llevaron a agitación en vórtex por 15 segundos; mediante centrifugación a 12.000 rpm durante 15 minutos a $4^{\circ} \mathrm{C}$ se obtuvo una fase acuosa, la cual fue separada a un tubo nuevo y tratada con $500 \mathrm{ml}$ de isopropanol frío durante 15 minutos; después de centrifugar a 12.000 rpm durante 10 minutos $\left(4^{\circ} \mathrm{C}\right)$, el ARN obtenido se lavó con $500 \mu \mathrm{l}$ de etanol al $75 \%$; una vez evaporado el etanol, el ARN fue resuspendido en $20 \mu \mathrm{l}$ de agua tratada con dietilpirocarbonato (DEPC, Sigma) y 20 unidades de inhibidor de ARNasas (Invitrogen). Como controles de extracción a partir de tejido, se utilizaron cerebros provenientes de ratones infectados previamente con virus de la fiebre amarilla (control positivo) (21) y cerebros de ratones no infectados (control negativo).

\section{Reacción en cadena de la polimerasa de transcriptasa inversa}

Se tomaron $7,5 \mu$ de cada muestra de ARN y se sometieron a reacción de transcripción inversa en las siguientes condiciones: $3 \mu \mathrm{l}$ de tampón $5 \mathrm{X}$ para transcripción (Invitrogen), 0,75 $\mu$ de una mezcla $10 \mathrm{mM}$ de cada uno de los desoxinucleótidos trifosfato (dNTP, Promega), 1,5 $\mu \mathrm{l}$ de ditiotreitol (DTT) 0,1M (Invitrogen), 0,75 $\mu \mathrm{l}$ de enzima transcriptasa inversa M-MLV $200 \mathrm{u} / \mu \mathrm{l}$ (Invitrogen) y 1,5 $\mu \mathrm{l}$ del iniciador antisentido JM2673 $10 \mu \mathrm{M}$ previamente reportado (21); la reacción de transcripción inversa se realizó a $37^{\circ} \mathrm{C}$ durante 1 hora y el ADNc generado se utilizó como templado en una reacción de PCR con los iniciadores específicos para fiebre amarilla reportados por Méndez et al. (21); estos iniciadores se diseñaron sobre la secuencia genómica de la cepa prototipo Asibi para amplificar un fragmento de 424 pb en la región de unión de los genes E/NS1.

Las condiciones de la reacción fueron las siguientes: $5 \mu \mathrm{l}$ de tampón 10x para PCR (Corpogen), $3 \mu \mathrm{l}$ de $\mathrm{MgCl} 225 \mathrm{mM}$ (Corpogen), 1 $\mu$ de una mezcla $10 \mathrm{mM}$ de cada uno de los desoxinucleótidos trifosfato (dNTP, Promega), 1 $\mu \mathrm{l}$ del iniciador sentido (JM2249) $10 \mu \mathrm{M}, 1 \mu \mathrm{l}$ del iniciador antisentido (JM2673) $10 \mu \mathrm{M}$ y 2,5 U de enzima Taq polimerasa (TucanTaq, Corpogen), en un volumen final de $50 \mu \mathrm{l}$; la reacción se llevó a cabo en un termociclador (Perkin Elmer) con 35 ciclos de denaturación $\left(94^{\circ} \mathrm{C}\right)$ anillaje $\left(55^{\circ} \mathrm{C}\right)$ y extensión $\left(72^{\circ} \mathrm{C}\right)$; como controles de reacción se utilizaron $5 \mu \mathrm{ADNc}$ de virus de la fiebre amarilla obtenido previamente a partir de sobrenadante de cultivo (control positivo de amplificación) y $5 \mu \mathrm{l}$ de agua estéril (control negativo de amplificación). Los productos de amplificación obtenidos por PCR fueron observados en un gel de agarosa al $1 \%$ teñido con bromuro de etidio.

\section{Histopatología e inmunohistoquímica}

El diagnóstico basado en inmunohistoquímica se realizó a partir de tejido fijado en formol tamponado al $10 \%$ e incluido en parafina, realizando cortes de $3 \mu \mathrm{m}$ en láminas con poli-L-lisina. Las láminas se colocaron en el horno a $60^{\circ} \mathrm{C}$ para desparafinarlas y, posteriormente, se pasaron por xilol y alcohol en diferentes concentraciones $(100 \%, 95 \%$ y $70 \%)$. A continuación, las láminas se lavaron y rehidrataron en agua destilada y tratadas en solución de tripsina 0,05\%, pH 7,8 a 


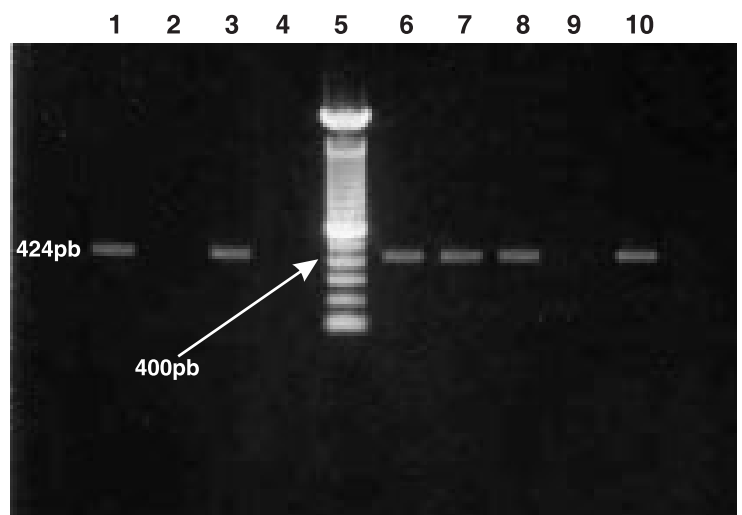

Figura 1. Electroforesis en gel de agarosa al $1 \%$ teñido con bromuro de etidio, de los productos amplificados con los iniciadores JM2249/JM2263 del virus de la fiebre amarilla. Carril 1: control positivo de extracción; carril 2: control negativo de extracción; carril 3: control positivo de amplificación; carril 4: control negativo de amplificación; carril 5: marcadores de peso molecular (100 bp DNA ladder, Invitrogen); carril 6: muestra vereda Los Bezotes (Cesar); carril 7: muestra vereda Pitillas (Cesar); carril 8: muestra vía La Mesa (Cesar) carril 9: muestra vereda La Paz (Cesar); carril 10: muestra del Magdalena.

$37^{\circ} \mathrm{C}$ durante 30 minutos; después de ser lavadas con PBS, se incubaron con peróxido de hidrógeno $3 \%$ durante 30 minutos y luego incubadas nuevamente con suero normal de caballo durante media hora. Después de retirar el exceso de suero, cada lámina fue tratada con una dilución 1:1.000 del anticuerpo primario (yellow fever 17D-ascitic fluid immune mouse, CDC, Atlanta) contra fiebre amarilla e incubada por una hora a temperatura ambiente. Posteriormente, se realizaron tres lavados con PBS y se adicionó una dilución 1:300 del anticuerpo secundario (Biotinylated anti Mouse $\lg G(H+L), B A-2000$ Vector) por una hora incubado en cámara húmeda a temperatura ambiente. Después de lavar nuevamente con PBS, se adicionó la estreptavidina (dilución 1:100; alcaline phosphatase streptavidin, SA-5100 Vector) y se incubó durante 1 hora, tiempo después del cual se lavó con PBS y se reveló con el estuche comercial New Fuchsin substrate system (K-0698, DAKO cytomation). Para facilitar la visualización, se hizo contraste con hematoxilina durante 1 minuto y se pasó por agua amoniacal al $5 \%$ durante 3 segundos. Posteriormente, se lavó con agua destilada y se realizó el montaje con cito-resina entre lámina y laminilla $(22,23)$.

\section{Resultados}

De las cinco muestras de tejido hepático procesadas por la técnica de RT-PCR, se observó que tres de las pertenecientes a monos encontrados muertos en el departamento del Cesar (vereda los Bezotes, vereda Pitillas y vía La Mesa), así como el tejido remitido por el departamento del Magdalena, mostraron en el gel de agarosa una banda clara y única de amplificación (figura 1); al comparar con los patrones de peso molecular utilizados en el gel y con los controles positivos de extracción y reacción, las bandas obtenidas para cada muestra pertenecen al tamaño esperado (424 pb) según la posición de los iniciadores utilizados; la muestra restante obtenida en la vereda La Paz del departamento del Cesar y que llegó al laboratorio en malas condiciones de conservación y refrigeración, así como los controles negativos de extracción y de reacción, no mostraron amplificación.

Por otro lado, el examen microscópico de las muestras de tejido reveló la típica necrosis mediazonal confluente; en algunos campos se observó necrosis generalizada en las diferentes zonas del lobulillo hepático. En las mismas cuatro muestras que fueron amplificadas por PCR, también se observaron cambios grasos, poca respuesta inflamatoria y formación de numerosos cuerpos de Councilman (figura 2). La inmunohistoquímica con anticuerpos policlonales contra fiebre amarilla demostró la presencia de proteínas virales dentro de los hepatocitos mediozonales (figura 3). En la muestra proveniente de La Paz (Cesar), que resultó negativa por PCR, no se observaron cambios compatibles con infección por fiebre amarilla; así mismo, el ensayo inmunohistoquímico realizado a esta muestra resultó negativo.

\section{Discusión}

En Colombia, la fiebre amarilla, en su ciclo epidemiológico urbano mediado por el mosquito vector Aedes aegypti, ha sido descrita desde el siglo XVII cuando se convirtió en un factor determinante para dificultar las intenciones conquistadoras de diversas tropas europeas que se vieron afectadas por la mortal enfermedad 


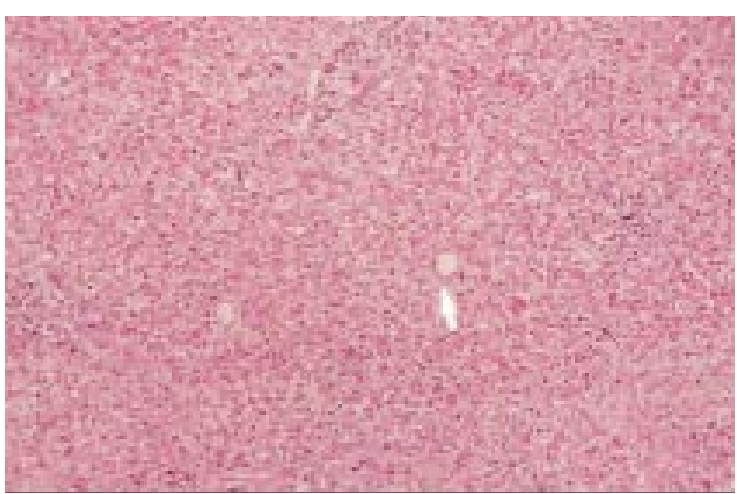

Figura 2. Microfotografía hepática H\&E 20X, se identifica necrosis generalizada en las diferentes zonas del lobulillo hepático, la flecha indica el área perivenular, el infiltrado inflamatorio es mínimo.

$(24,25)$. Desde entonces, la enfermedad se convirtió en una constante, principalmente en el Atlántico y a lo largo del río Magdalena. Aunque el último brote urbano en Colombia ocurrió en 1928 (El Socorro, Santander), el ciclo selvático de la enfermedad se ha venido presentando de forma endémica, principalmente en zonas boscosas cercanas a los ríos Magdalena, Guaviare, Catatumbo, Orinoco y Amazonas, y se han confirmado casos humanos todos los años desde 1934 cuando se implementó el programa de diagnóstico basado en viscerotomía $(6-13,26)$.

A pesar de las medidas de vigilancia y control lideradas por el Instituto Nacional de Salud y el Ministerio de la Protección Social, durante los

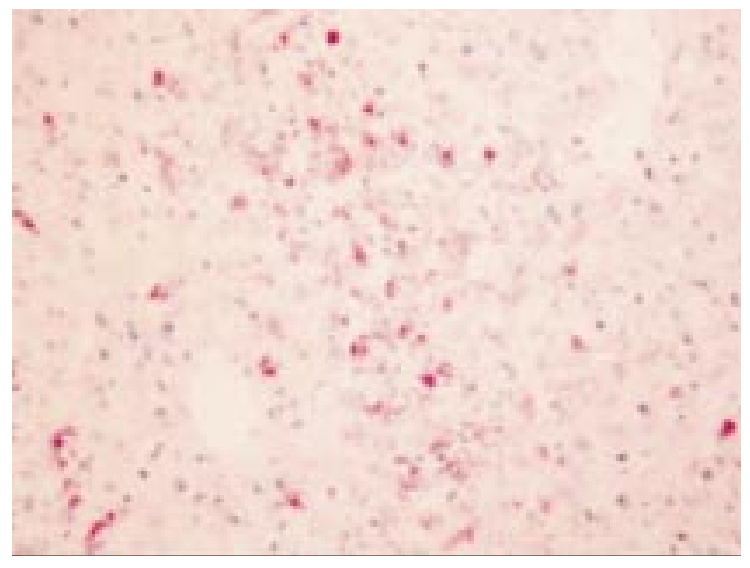

Figura 3a. Microfotografía hepática con inmunorreactividad positiva para los antígenos amarílicos, con la técnica avidinabiotina-fosfatasa alcalina. 40X. meses de junio y agosto de 2003 se presentó un brote epidémico en áreas selváticas del Catatumbo, departamento Norte de Santander, donde se confirmaron más de 64 casos con $35 \%$ de mortalidad (11-13); los más afectados fueron hombres entre 15 y 45 años que, por condiciones de trabajo (taladores, aserradores, mineros, trabajadores agrícolas), se vieron obligados a internarse en áreas selváticas exponiéndose así a la infección.

Posteriormente, a finales del 2003 y como una posible expansión del brote iniciado en Norte de Santander debido a la migración de población hacia la Sierra Nevada de Santa Marta, se observó un incrementó en el número de casos sospechosos humanos en el norte del país (11-13). Así, para mediados de enero de 2004 ya se habían confirmado 29 casos pertenecientes a los departamentos de La Guajira (7 casos), Magdalena (14 casos) y Cesar (ocho casos) (11).

Así mismo, durante la semana epidemiológica 51 se aumentaron los registros de epizootias en primates no humanos de los parques ecológicos pertenecientes a estos departamentos, coincidiendo claramente con la aparición de casos humanos, principalmente en Cesar.

Este incremento en el número de casos humanos se correlaciona, además, con los hallazgos de laboratorio con la técnica de RT-PCR para las muestras de monos obtenidas a finales de

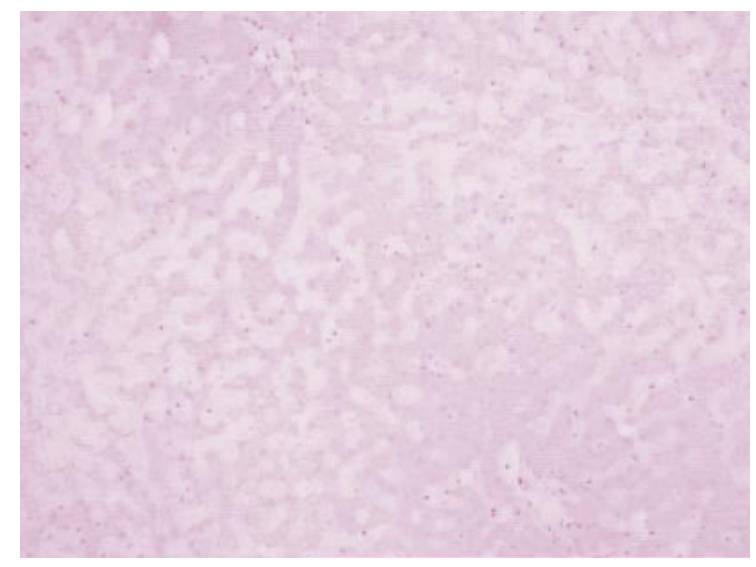

Figura 3b. Microfotografía hepática con inmunorreactividad negativa para los antígenos amarílicos, con la técnica avidina-biotina-fosfatasa alcalina. 40X. 
diciembre de 2003 y permite hacer un seguimiento durante los meses de enero y junio de 2004, tanto en el departamento del Cesar como en el Magdalena, lo que demuestra la importancia de sensibilizar la vigilancia en reservorios selváticos. Infortunadamente, aunque los residentes de las zonas afectadas reportaron el hallazgo de monos muertos durante el brote, la gran mayoría de éstos no se recolectaron o se encontraban en un avanzado estado de descomposición al momento de su hallazgo, lo que hizo la muestra inadecuada para el diagnóstico.

Por otro lado, observamos en nuestro estudio que la técnica de RT-PCR utilizando los iniciadores específicos previamente reportados para el diagnóstico de la fiebre amarilla, se correlaciona perfectamente con los hallazgos del estudio histopatológico. Si bien la muestra proveniente de La Paz, Cesar, que resultó negativa por PCR, no se encontraba en buenas condiciones de conservación por lo que se pudo haber alterado la estructura del ARN viral, tampoco se reportaron hallazgos histológicos compatibles con la infección por el virus en esta muestra, lo cual concuerda con los datos obtenidos por la técnica molecular; por otro lado, los resultados obtenidos por amplificación, demuestran una banda única muy evidente que refleja la especificidad del ensayo.

Teniendo en cuenta las condiciones epidemiológicas de la enfermedad en áreas endémicas y como una estrategia de control para evitar la reurbanización de la fiebre amarilla en Colombia, la vigilancia en zonas de alto riesgo debe incluir no sólo la implementación de sitios centinela que permitan determinar la presencia de casos humanos $(9,21,27,28)$ sino, además, un seguimiento a epizootias que representan riesgo de infección en área selvática $(16,19)$. Así, la detección precoz del virus de la fiebre amarilla en tejido proveniente de monos muertos, además de ser una clara evidencia de la actividad selvática viral, constituye un sistema de alerta temprana que indica la necesidad de intensificar medidas de control, como vacunación en las áreas cercanas, estudio de vectores tanto selváticos como urbanos y búsqueda activa de casos que puedan desencadenar un brote o epidemia.
Por otra parte, la técnica de amplificación ya estandarizada nos permitirá realizar análisis de las secuencias para definir patrones de desplazamiento de los diferentes genotipos virales que pueden estar circulando en áreas endémicas, donde la gran cantidad de vectores y posibles reservorios favorecen la variabilidad, tal como se ha demostrado en diversas regiones de África, Brasil y Perú $(16,18,29,30)$.

Aunque el estudio histopatológico acompañado de la inmunohistoquímica en cortes de hígado aún es el método de elección para realizar el diagnóstico $(23,26)$, los resultados obtenidos en nuestro laboratorio indican que la aplicación de técnicas moleculares relativamente rápidas (ocho horas incluyendo la lisis del tejido) y sencillas tales como la RT-PCR a partir de muestras de tejido para la detección del virus fiebre amarilla, se convierten en un complemento esencial para una vigilancia epidemiológica eficiente $(21,22,28)$, que incluya la evaluación de epizootias en zonas vulnerables que por condiciones socioculturales representen un vehículo ideal para la reurbanización de la enfermedad.

\section{Agradecimientos}

Los autores agradecen la colaboración de los Laboratorios de Salud Pública de Cesar y Magdalena, por su colaboración con la recolección y remisión de las muestras al Instituto Nacional de Salud.

\section{Conflicto de intereses}

Los autores manifiestan que no existe ningún tipo de conflicto de interés económico o moral para la publicación de este manuscrito.

\section{Financiación}

Este trabajo ha sido soportado con los recursos asignados a la Subdirección Red Nacional de Laboratorios del Instituto Nacional de Salud para la vigilancia de la fiebre amarilla en Colombia.

\section{Referencias}

1. Monath TP. Yellow fever: an update. Lancet Inf Dis. 2001;1:11-20.

2. Digoutte JP, Cornet M, Deubel V, Downs WG. Yellow fever. En: Porterfield JS, editor. Exotic viral infections. London: Chapman \& Hall Medical; 1995. p.67-102. 
3. Oyewale T. Yellow fever in Africa: public health impact and prospects for control in the $21^{\text {st }}$ century. Biomédica. 2002;22:178-93.

4. Robertson SE, Hull BP, Tomori O, Bele O, LeDuc JW, Esteves K. Yellow fever. A decade of re-emergence. JAMA. 1996;276:1157-62.

5. Tesh R. Viral hemorrhagic fevers of South America. Biomédica. 2002;22:178-93.

6. Vidales H, Buitrago B, Sanín LH, Morales A, Groot H. Estudio de un brote epidémico de fiebre amarilla selvática en el piedemonte de la Sierra Nevada de Santa Marta, 1979. Biomédica. 1981;1:171-8.

7. Groot H, Morales A, Romero M, Ferro C, Prías E, Vidales H, et al. Estudios de arbovirus en Colombia en la década de 1970. Biomédica. 1996;16:331-44.

8. Cáceres DC. La fiebre amarilla y su vigilancia en salud pública. Inf Quinc Epidemiol Nac. 1999;4:7-11.

9. García I, Velandia MP, Olano VA, Molina J, Salas T, Bernal MP, et al. Sistema de vigilancia centinela sobre enfermedades febriles transmitidas por vectores con énfasis en fiebre amarilla, dengue y malaria en los departamentos de Caquetá, Nariño, Putumayo, La Guajira y Valle, 2000. Inf Quinc Epidemiol Nac. 2001;6:1-8.

10. Porras A, de la Hoz F, Velandia MP, Ramírez O, Buitrago LS, Herrera M, et al. Informe epidemiológico sobre un posible brote de fiebre amarilla en el departamento del Meta, 30 de mayo a $1^{\circ}$ de junio de 2001. Inf Quinc Epidemiol Nac. 2001;6:273-6.

11. Vera MJ, Velandia MP, Rodríguez G, Neira M, Bernal MP, Méndez JA, et al. Fiebre amarilla selvática en la región del Catatumbo, Colombia 2003. Inf Quinc Epidemiol Nac. 2004;9:49-53

12. Velandia MP, Vera MJ, García I, Bernal MP, Méndez JA, Olano V, et al. Fiebre amarilla. Inf Quinc Epidemiol Nac. 2004;9:148-56.

13. Vera N. Situación de la fiebre amarilla en Colombia, semanas 1 a 35 de 2005. Inf Quinc Epidemiol Nac. 2005; $10: 241-7$

14. Barros ML, Boecken G. Jungle yellow fever in the central Amazon. Lancet. 1996;348:969-70.

15. Barrett AD, Monath TP. Epidemiology and ecology of yellow fever virus. Adv Virus Res. 2003;61:291-315.

16. Weaver SC, Barrett AD. Transmission cycles, host range, evolution and emergence of arboviral disease. Nat Rev Microbiol. 2004;2:789-801.

17. Lepiniec L, Dalgarno L, Huong VT, Monath TP, Dogoutte JP, Deubel V. Geographic distribution and evolution of yellow fever viruses based on direct sequencing of genomic cDNA fragments. J Gen Virol. 1994;75:417-23.
18. Mutebi JP, Wang H, Li L, Bryant JE, Barret AD. Phylogenetic and evolutionary relationships among yellow fever virus isolates in Africa. J Virol. 2001;75:6999-7008.

19. Vasconcelos PF, Costa ZG, Travassos Da Rosa ES, Luna E, Rodrigues SG, Barros VL et al. Epidemic of jungle yellow fever in Brazil, 2000: Implications of climatic alterations in disease spread. J Med Virol. 2001;65:598-604.

20. Rodríguez G, Velandia M, Boshell J. Fiebre amarilla: la enfermedad y su control. Bogotá: Instituto Nacional de Salud; 2003.

21. Méndez JA, Rodríguez G, Bernal MP, Calvache D, Boshell J. Detección molecular del virus de la fiebre amarilla en muestras de suero de casos fatales humanos y en cerebros de ratón. Biomédica. 2003;23:232-8.

22. Monath TP, Ballinger ME, Miller BR, Salaun JJ. Detection of yellow fever viral RNA by nucleic acid hybridization and viral antigen by immunocytochemistry in fixed human liver. Am J Trop Med Hyg. 1989;40:663-8.

23. Ricaurte O, Sarmiento L, Caldas ML, Rodríguez G. Evaluación de un método inmunohistoquímico para el diagnóstico de la fiebre amarilla. Biomédica. 1993; 13:15-9.

24. Groot H, Boshell J. Dengue, dengue hemorrágico y fiebre amarilla. En: Chalem F, Escandon JE, Campos $\mathrm{J}$, Esguerra R, editores. Medicina interna. Bogotá: Doyma Andina S.A.; 1992. p.1389-95.

25. Groot H. Resumen de notas históricas sobre la fiebre amarilla en Colombia. Iatreia. 2004;17:14.

26. Rodríguez G, Ordóñez N, Boshell J. 1998: un año sin casos de fiebre amarilla por viscerotomía. Inf Qinc Epidemiol Nac. 1999;4:3-7.

27. Monath TP, Nystrom RR. Detection of yellow fever virus in serum by enzyme immunoassay. Am J Trop Med Hyg. 1984;33:151-7.

28. Deubel V, Huerre M, Cathomas G, Drouet MT, Wuscher N, LeGuenno B, et al. Molecular detection and characterization of yellow fever virus in blood and liver specimens of a non-vaccinated fatal human case. J Med Virol. 1997;53:212-7.

29. Wang E, Weaver SC, Shope RE, Tesh RB, Watts DM, Barret AD. Genetic variation in yellow fever virus: duplication in the 3'noncoding region of strains from Africa. Virology. 1996;225:274-81.

30. Bryant JE, Barret AD. Comparative phylogenies of yellow fever isolates from Peru and Brazil. FEMS Immunol Med Microbiol. 2003;39:103-18. 